\title{
CORRECTIONS TO A PAPER
}

"On Factors of Numbers of the Form $\left\{x^{(2 n+1) t} \pm 1\right\} \div\left\{x^{x} \pm 1\right\}$," by Professor Sanjana, in Vol. XXVI. of the Proceedings.

Page 68, last line but one, for " $\sin \frac{3 \pi}{3} " \operatorname{read} " \sin \frac{3 \pi}{4}$."

Page 70, line 20, for “ 15258501 ” read " 15258358501 ."

Page 74, line 2, for " $+\frac{x^{2 n+1}+1}{x+1}$ " read " $\times \frac{x^{2 n+1}+1}{x+1}$."

Page 77, last line but one, for "4.1.744 287 " read "4.1.7.44 287." Page 79, line 18, for "products" read "product."

Page 83, lines 6 and 8, for "same" read "some."

Page 84, footnote, for " right" read " rigid." 